\title{
Attitudes and knowledge of nurse practitioners towards traditional healing, faith healing and complementary medicine in the Northern Province of South Africa
}

\author{
K Peltzer, Ph D, Department of Psychology, University of the North \\ LB Khoza, Ph D, Department of Nursing, University of the North
}

\begin{abstract}
Objective: To investigate the attitudes and knowledge of nurses towards traditional healing, faith healing and complementary therapies in the Northern Province in South Africa.

Design: Survey of nurses.

Setting: Registered professional nurses at health centres and clinics.

Participants: 84 registered professional nurses

Results: Nurse's perceptions were basically positive toward ethnomedical therapy (traditional healing, faith healing and complementary medicine); this also included their integration into the primary health care system. Mean ratings for referral to a faith healer was 2.7 , followed by complementary medicine (2.6) and traditional healing (2.2). Although low rates of referrals to ethnomedical therapists were practised, it was done so mainly in the patient's interest and not as a last resort for chronic or terminal illness. Most did not discuss with a patient benefits of traditional healing but $71 \%$ discussed the possible harmful effects. However, the majority discussed the benefits rather than harmful effects of faith healing. With respect to mean ratings on knowledge, faith healing was considered the most important (4.3), followed by complementary medicine (4.2), and traditional healing (4.1).

Conclusion: Faith healing was considered as more important than complementary medicine and traditional healing. Implications are relevant for nursing health care and policy.
\end{abstract}

\section{Introduction}

There is some resurgence of interest in traditional healing methods as practised by indigenous South Africans (Freeman \& Motsei 1992: 1183). Although traditional and western health care systems have operated side-by-side in South Africa since the advent of the Europeans, western healing has enjoyed greater formal (i.e. official) acceptance by successive previous governments because it was seen to be based on scientific and rational knowledge. In contrast, traditional and faith healing has been officially frowned upon and marginalised because it was perceived to be based on mystical and magical religious beliefs (Freeman \& Motsei 1992: 1183). Before the April 1994 elections the African National Congress (ANC) proposed the following in its National Health Plan:

Traditional healing will become an integral and recognised part of health care in South Africa. Consumers will be allowed to choose whom to consult for their health care, and legislation will be changed to facilitate controlled use of traditional practitioners.

Soon after the elections, the new Government of National Unity formalised this policy in its Reconstruction and Development Plan (RDP)(African National Congress 1994b: 3-5.).

There are deep divisions, fueled by mutual suspicion and lack of communication, between traditional and other complementary healers and medical and social workers. This is not in the interest of people who use all types of healers. The Reconstruction and Development Programme (RDP) must aim to improve communication, understanding and cooperation between different types of healers (African National Congress 1994b: 35.). Hopa, Simbaye and du Toit (1998: 8) have investigated the perceptions on integration of traditional and western healing in the new South Africa. Different stakeholders (psychiatrists, medical doctors, psychologists, traditional healers and consumers) favoured the formal cooperation option for the integration of the two health systems.

As noted in South Africa traditional and faith healers play an important role in health care (Peltzer 1998: 191. Peltzer 1999: 387, Pretorius 1989: 101, Shai-Mahoko 1996: 31). This may be expressed by the fact that for many South Africans the first choice of treatment is the traditional healer (Farrand 1984: 779, Louw \& Pretorius 1995: 52f., Mabunda 1999: 34-36, Swartz 1986: 280). Mabunda (1999: 10) surveyed hospital patients and staff, church members and university students in the Northern Province in South Africa and found that -according to the participants- a number of diseases can be best prevented or cured by traditional healing, e.g. witchcraft (like Seješo and Sefolane) and ancestor (badimo) related problems, "traditional" diseases like Hlogwana (pulsating fontanelle; litt. 'little head'), Makgoma (assortment of ailments which follows the breach of particular taboos), infertility, sexually transmitted diseases, asthma, mental disorders, epilepsy, and diarthea while biomedicine was considered successful in diseases such as tuberculosis, chicken 
pox. AIDS, hypertension, diabetes, malaria, measles, cancer, anemia, mental retardation, ulcers.

Freeman and Motsei (1992: 1184) stated that there are broadly three types of traditional healers available to South African consumers. First the traditional doctor or inyanga. This is generally a male who uses herbal and other medicinal preparations for treating disease. Second the dingaka (Sotho). This is usually a woman who operates within a traditional religious supernatural context and acts as a medium with the ancestral shades. Third the faith healer who integrates Christian ritual and traditional practices. In addition, Fenn (1998: 3-4) gives a guide to complementary therapies in South Africa including hypnotherapy, regression therapy, rebirthing, past life regression, psychoneuroimmunology (PNI) therapy, astrological counselling, tarot counselling, metaphysical counselling, etc.

Nemec (1980: 2) states that two-thirds of the people in the world today depend on the healing methods used by their ancestors, and in some areas it is the only form of care available and with which people are comfortable. In every culture, illness, the responses to it, individuals experiencing it and treating it, and the social institutions relating to it are all systematically interconnected. The totality of these interrelationships is the health care system. Included here are patterns of belief about the causes of illness, the norms governing the choice and evaluation of treatment, and socially legitimated roles, power relationships, interacting setting and institutions. Patients and healers are basic components of such systems and thus are embedded in specific configurations of cultural meanings and social relationships (Kleinman 1980: 24). Original African concepts of disease causation incorporate belief in natural or God-given illness, and in supernatural forces, including sorcery, witchcraft, spirit disturbance, and in breaching of taboos or breaking kinship rules or religious obligations. The causal framework emerges from a fundamentally unitarian conception of nature which encompasses the physical world and a sociological environment that expresses continuity between the living and the dead, together with the mystical forces of the universe (WHO 1976: 10-12). Most traditional medical theories have a social and religious character and emphasize prevention and holistic features. Traditional medical practices are usually characterized by the healer's personal involvement, by secrecy and a reward system. Biomedical theory and practice show an almost opposite picture: asocial, irreligious, curative and organ-directed, and professional detachment (Van der Geest 1997: 903).

The role of traditional and faith healing and complementary medicine in the future of health care in South Africa largely depend on its acceptance by the established medical community. Definitions used here are: traditional healers are herbalists or diviners, faith healers are prophets, priests, pastors who heal, and complementary medicine includes therapies such as acupuncture, hypnosis, homeopathy, chiropractic, massage, touch therapy, vitamin therapy, etc. Complementary or alternative medicine is here to cover Western practices although traditional or faith healing could also be understood as complementary medicine (Fenn 1998:11).

Several developing countries in Africa, Asia and Latin America have experimented with the integration of traditional and Western health care systems, but the case of traditional medicine in China is perhaps the best model for the successful integration of the two medical systems (Lesley in Pretorius 1999: 4). WHO has strongly advocated promotion of cooperation between traditional and modern health practitioners.

In Botswana 'United Health Committees have been established aiming at creating a dialogue between the different types of health professionals (Akerele 1987: 16).

There is a general lack of studies in South Africa investigating the attitude and knowledge of nurse practitioners towards nonbiomedical or ethnomedical therapies. Mahape and Peltzer (1998: 39) studied the attitudes of psychiatric nurses towards traditional

healers as providers of mental health in South Africa. Findings showed that the nurses agree

that it is possible to develop a working partnership with traditional healers in mental health

care, provided formal policy guidelines structuring the practice of traditional healing are specified.

To assess attitudes and knowledge with respect to traditional healing, faith healing and complementary medicine a survey was conducted among nurse practitioners in the Northern Province in South Africa.

The Northern Province is the most impoverished of the nine provinces in South Africa with a real GGP per capita of R 1712 Rand in 1994. The area is largely rural with $91 \%$ of the inhabitants living in non-urban areas where accesses to health care facilities are inadequate (e.g. 2.4 hospital beds per 1000 people in 1992 and a physician: population ratio of less than 1:20000). Health indicators are low (an infant mortality rate of 57:1000) (Development Bank of Southern Africa 1998: 10).

\section{Method}

\section{Sample and procedure}

The sample consisted of nurse practitioners working at the randomly selected 9 health centres and 14 clinics of the Lowveld and Northern regions of the Northern Province. The two regions comprised of 18 health centres of which every second, alphabetically chosen, was selected. The study only utilised clinics found in the Lowveld because of their geographic accessibility. Every sixth of a total of 83 clinics in the Lowveld was selected for the study. At all these 9 health centres and 13 clinics nurse practitioners were chosen by convenience. The final sample included 84 nurse practitioners; 20 were discarded because their questionnaires were not complete. The nurse practitioners were given a self-administered questionnaire after informed consent was taken from them and anonymity and confidentiality was assured.

The nurses were 78 female $(92.9 \%)$ and 6 male $(7.1 \%)$ in the age range of 23 to 58 years ( $M$ age $38.0 \mathrm{yr}$., $S D=8.0$ ). All participants were African (black). The number of years of health service ranged from 3 to 27 years, with a mean of 13.0 years $(S D=6.9)$. Permission to conduct the study was given by the University of the North Ethics Committee and the Northern Province Department of Health and Welfare.

\section{Measuring instrument}

The questionnaire was a modified and expanded version of what Boucher and Lenz (1992: 60-61) had used with American physicians. Section 1 included demographic data: sex, age, number of years of nursing practice, and ethnicity. Section 2 
had 8 items on the perceptions about traditional healing (such as 'Is traditional healing a threat or benefit to the public', which was rated from $1=$ extreme threat to $5=$ extreme benefit), 8 items on faith healing and 8 items on complementary medicine. Section 3 asked for referral information: 3 items on referrals to traditional healer (such as 'Have you ever referred or recommended a patient to a traditional healer?' with the response options 'Yes', 'No of cases' and 'No'), 3 items on faith healer and 3 items on complementary medicine practitioner; 6 items for each ethnomedical method for possible reasons for referral (such as patient interest, as a last resort (chronic or terminal illness), know healer or complementary practitioner with good reputation, personally found it beneficial, for nonspecific complaints and other reasons); and 8 items on discussing benefits and harmful effects for each ethnomedical method (such as 'Have your ever discussed with a patient the possible benefits of faith healing?'). Section 4 identified the knowledge about various ethnomedical nesses regarding the appropriate referral agency (psychiatrist, medical practitioner, clinical psychologist, traditional healer, faith healer, and complementary medicine practitioner). Finally, open questions asked for case descriptions of patients who had consulted a traditional healer, faith healer or complementary medicine practitioner before consulting the nurse and case descriptions of patients he or she had referred or recommended to a traditional healer, faith healer or complementary medicine practitioner.

A pilot study was conducted on 20 nurses to test the reliability of the questionnaire. The same nurses (from the pilot study) were asked to respond to the questionnaire after 3 weeks. A test-retest reliability of .82 was found.

\section{Data analysis}

Reported case studies were content analysed, and descriptive statistics were calculated using SPSS version 8.0 .

\section{Table 1: Nurses 'perceptions of traditional healing, faith healing and complementary medicine by agreed frequency and in percent}

\begin{tabular}{|c|c|c|c|}
\hline Statement & 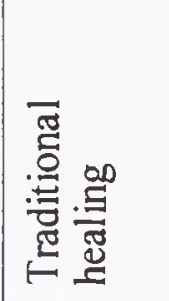 & 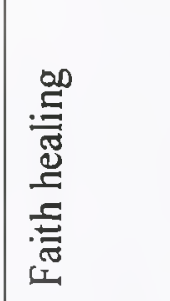 & 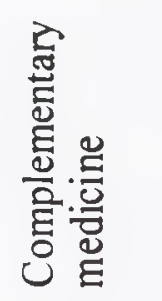 \\
\hline & Fre. $(\%)$ & Fre. $(\%)$ & Fre. $(\%)$ \\
\hline So-called $\mathrm{X}^{*}$ ethnomedical method is quackery & $39(46)$ & $34(41)$ & $41(49)$ \\
\hline $\mathrm{X}$ ethnomedical method has no true impact & $34(41)$ & $28(33)$ & $35(42)$ \\
\hline No strong feelings & $43(51)$ & $45(54)$ & $51(61)$ \\
\hline A number of $\mathrm{X}$ ethnomedical methods hold promise & $58(69)$ & $55(65)$ & $54(64)$ \\
\hline $\begin{array}{l}\text { Has the integration of } \mathrm{X} \text { ethnomedical method into the } \\
\text { national health care system some (major) positive } \\
\text { impact on patient satisfaction? }\end{array}$ & $78(93)$ & $82(98)$ & $65(77)$ \\
\hline $\begin{array}{l}\text { Has the integration of } \mathrm{X} \text { healing/medicine into the } \\
\text { national health care system some (major) negative } \\
\text { impact on patient satisfaction? }\end{array}$ & $64(76)$ & $65(77)$ & $41(49)$ \\
\hline
\end{tabular}

*X stands for each respective treatment modality (traditional healing, faith healing and complementary medicine)

treatment methods (such as acupuncture and herbal therapy, which was anchored from $1=$ unfamiliar to $3=$ understanding of proposed uses). Section 5 rated on a 5-point scale 9 types of evidence for the evaluation of ethnomedical methods (such as 'prospective clinical randomized controlled trials and case reports in complementary' or 'alternative medicine journals', which was rated from $1=$ this type of evidence would have no impact on my thoughts about ethnomedical therapies to $5=$ this type of evidence would convince me that the treatment us highly effective). Section 6 asked to rate 14 problems or ill-

\section{Results Perceptions}

One the one hand so-called ethnomedical methods were seen as quackery by $41 \%$ for faith healing, $46 \%$ traditional healing and $49 \%$ for complementary healing, and on the other hand $69 \%$ felt that traditional healing held promise for the treatment of symptoms, conditions, and/or diseases, $65 \%$ for faith healing and $64 \%$ for complementary medicine, respectively. More 
ethnomedical methods had no true impact on the treatment of symptoms, conditions, and/or diseases. It appeared that it depended much on the type and expertise of the particular ethnomedical method whether it was considered promising or quackery. Similarly, the overwhelming majority (surprisingly) of the nurse practitioners felt that the integration of faith healing $(98 \%)$, traditional healing $(93 \%)$ and complementary medicine $(77 \%)$ into the national health care system had some positive impact on patient satisfaction. However, many of the nurses also perceived that the integration of ethnomedical medicine (traditional healing: $76 \%$, faith healing: $77 \%$, complementary medicine: $49 \%$ ) into the national health care system had a major negative impact on patient satisfaction (see Table 1).

Regarding the potential threat or benefit of ethnomedical methods to the public, the majority ( $77 \%$ to $87 \%$ ) felt that they had a moderate benefit. However, on the other hand between $68 \%$ and $75 \%$ felt that they were a moderate threat, even $63 \%$ felt faith healing to be an extreme threat, traditional healing $52 \%$ and faith healing $52 \%$ respectively (see Table 2 ).

\section{Table 2 : Threat or benefit of traditional healing, faith healing, and complementary medicine to the public in percent}

Nurse practitioners would more likely refer a patient to a faith healer, second to a complementary medicine practitioner and last to a traditional healer (see Table 4).

A list of 5 possible reasons for referral was provided. Participants were asked to check each reasorı that applied. An 'other' category was also added on the list so participants could write in their own responses. The most common reason for referral was 'patient interest', followed by 'personally found it beneficial', 'as a last resort' and 'acquaintance with a good therapist' (see Table 5).

Table 6 indicates "discussing benefits and harmful effects of referring a patient".

Almost half of the nurse practitioners (43\%) discussed the benefits of ethnomedical treatment with their patients. The nurse initiated the discussion about the benefits of faith healing (52\%, as opposed to $56 \%$ the patient) and complementary medicine ( $40 \%$, as opposed to $39 \%$ the patient) and the patient initiated

\begin{tabular}{|l|l|l|l|}
\hline Threat or benefit & Traditional healing & Faith healing & $\begin{array}{l}\text { Complementary } \\
\text { medicine }\end{array}$ \\
\hline Extreme threat & 52 & 63 & 52 \\
\hline Moderate threat & 68 & 68 & 75 \\
\hline No effect & 41 & 39 & 27 \\
\hline Moderate benefit & 77 & 87 & 87 \\
\hline Extreme benefit & 18 & 53 & 49 \\
\hline Don't know & 58 & 61 & 66 \\
\hline Missing cases & 08 & 07 & 07 \\
\hline
\end{tabular}

Referrals (rates, reasons, benefits and harmful effects, and problem type)

Three questions were asked about rates of referral. The first inquired whether nurse practitioners had ever referred or recommended a patient to an ethnomedical practitioner, the second asked whether it was likely they would do so in the future, and third asked about rates of referral or recommendation of a patient from a ethnomedical practitioner. Depending on the ethnomedical method only between $14 \%$ and $26 \%$ of the nurse practitioners had referred a patient. $38 \%$ would likely or very likely refer a patient to a faith healer in the future as opposed to $21 \%$ to a traditional healer. Most referrals were received from traditional healers $(55 \%), 33 \%$ from faith healers and $20 \%$ from complementary practitioners (see Table 3 ). the discussion about the benefits of traditional healing (30\% as opposed to $43 \%$ the patient). Clearly, the majority of the nurse practitioners $(71 \%)$ discussed the harmful effects of referral to a traditional healer, $58 \%$ said that they initiated the discussion and $51 \%$ said the patient initiated the discussion. Almost half of the nurses (42\%) also discussed the harmful effects of faith healing, and $38 \%$ said that they discussed the harmful effects of complementary medicine. Among the nurse practitioners who said that they discussed the possible harmful effects of ethnomedical treatment, the discussion was more often initiated by the nurses than by the patient.

Table 7 indicates 14 different problem types in relation to 6 different referral options. 
Overall, for most problems the medical practitioner seem to be perceived as the most appropriate for referral, followed by the clinical psychologist, psychiatrist, faith healer, complementary medicine practitioner and last the traditional healer. The five most frequently rated problems for referral for the medical practitioner were: (1) asthma, (2) allergies, (3) HIV/AIDS, (4) cancer, and (5) terminal illness; for the clinical psychologist: (1) sexual referred or recommended to a ethnomedical therapist are summarized below:

Table 5

From traditional healer:

To traditional healer:

\section{Table 3: Referrals of patients to and from traditional healers, faith healers and complementary practitioners in percent}

\begin{tabular}{|l|l|l|l|}
\hline & Referred to & $\begin{array}{l}\text { (Very) Likely to } \\
\text { refer in future to }\end{array}$ & $\begin{array}{l}\text { Received } \\
\text { referrals from }\end{array}$ \\
\hline Traditional healer & 14 & 21 & 55 \\
\hline Faith healer & 22 & 38 & 33 \\
\hline $\begin{array}{l}\text { Complementary medicine } \\
\text { practitioner }\end{array}$ & 26 & 35 & 20 \\
\hline Missing cases & & & \\
\hline
\end{tabular}

\section{Table 4: Mean ratings of nurses'referral to ethnomedical practitioners( $1=$ very unlikely to 5 $=$ very likely)}

\begin{tabular}{|l|l|l|}
\hline Referral modality & Mean & SD \\
\hline $\begin{array}{l}\text { How likely would you refer/recommend a patient to a faith } \\
\text { healer in the future }\end{array}$ & 2.74 & 1.44 \\
\hline $\begin{array}{l}\text { How likely would you refer/recommend a patient to an } \\
\text { complementary medicine practitioner in the future }\end{array}$ & 2.61 & 1.46 \\
\hline $\begin{array}{l}\text { How likely would you refer/recommend a patient to a traditional } \\
\text { healer in the future }\end{array}$ & 2.22 & 1.23 \\
\hline
\end{tabular}

ANOVA shows a significant difference between traditional healer and alternative practitioner $(F=5.159, p<.001)$

abuse, (2) depression, (3) anxiety, (4) psychosocial problems, and (5) insomnia; for the psychiatrist: (1) depression, (2) substance abuse, (3) stress, (4) psychosocial problems, and (5) anxiety; for the faith healer: (1) terminal illness, (2) bereavement, (3) stopping smoking, (4) cancer, and (5) anxiety; for the complementary medicine practitioner: (1) stopping smoking, (2) HIV/AIDS, (3) cancer, (4) allergies, and (5) asthma; and for the traditional healer: (1) HIV/AIDS, (2) cancer, (3) bereavement, (4) psychosocial problems, and (5) depression. This result seemed to indicate that the ethnomedical therapists have a function for supportive therapy (for terminal illness, HIV/AIDS, cancer, bereavement), minor psychiatric morbidity (stopping smoking, psychosocial problems, depression, anxiety), and psychosomatic disorders (allergies, asthma).

Nurses' case descriptions of patients who had consulted a traditional healer, faith healer or complementary medicine practitioner before consulting and case descriptions of patients
-Pulmonary tuberculosis

-HIV/AIDS

-Cancer

-Heart failure

-Herbal poisoning

-Depression

-Hallucinations

-Epilepsy

-Sexually transmitted diseases

-Yellow eyes

From faith healer:

To faith healer:

-Vaginal bleeding

-Depression

-Hypertension

-Diabetes 
-Epilepsy

-Asthma

-Social problems

-Terminal illness

-Psychological problems

-Hearing problems

From complementary medicine practitioner: To complemen -tary medicine practitioner:

-HIV/AIDS

-Insomnia

-Depression where most referrals were received from traditional healers $(55 \%)$ it was found that patients had often consulted traditional healers before coming to the clinic and that nurses frequently referred or recommended patients to a faith healer.

Referral case descriptions

From the case descriptions from a healer to the nurse and to a healer from the nurse selected examples are described below:

(1) "A lady of 35years old experienced infertility. She consulted a traditional healer. She was given some herbs to drink for to conceive a baby. After a day's dosage, she was brought to hospital in a critical state. She died of over dosage."

(2) “A lady was suffering from hypertension. A nurse referred

Table 5: Reasons for referral in percent

\begin{tabular}{|c|c|c|c|}
\hline Reasons for referral & 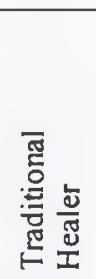 & 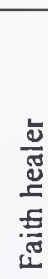 & 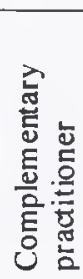 \\
\hline Patient interest & 35 & 74 & 62 \\
\hline As a last resort(chronic/terminal illness & 28 & 47 & 38 \\
\hline Knows therapist with good reputation & 30 & 39 & 37 \\
\hline Personally found it beneficial & 33 & 46 & 35 \\
\hline For nons pecific complaints & 18 & 30 & 31 \\
\hline Other reasons & 9 & 7 & 2 \\
\hline
\end{tabular}

On the basis of the case analysis and also as earlier stated

\section{Table 6: Discussing benefits and harmful effects of referral in percent}

\begin{tabular}{|c|c|c|c|}
\hline Benefits or harmful effects & 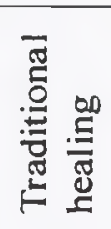 & 梽 & 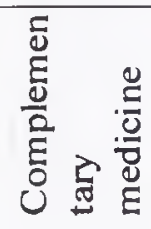 \\
\hline Discuss benefits & 31 & 60 & 37 \\
\hline Initiate discussion (nurse) & 30 & 52 & 40 \\
\hline Patient initiate discussion & 43 & 56 & 39 \\
\hline Combination of both & 27 & 47 & 32 \\
\hline Discuss harmful effects & 71 & 42 & 38 \\
\hline Initiate discussion (nurse) & 58 & 45 & 43 \\
\hline Patient initiate discussion & 51 & 37 & 42 \\
\hline Combination of both & 39 & 36 & 32 \\
\hline
\end{tabular}


her to a faith healer. I quote 'God can heal any illness, no matter what. The blood of Jesus was shed to wash our sickness and sins away. God can heal hypertension and diabetes if and only you believe and have faith in him'."
Survey participants were also queried about their knowledge of various ethnomedical therapies. Specific questions were asked concerning acupuncture, traditional healing, homeopathy, etc. Blank spaces were left for participants to write in other therapies. Participants were asked to rank their knowledge of

\section{Table 7: Problem type as appropriate for referral to various professions in percent}

\begin{tabular}{|c|c|c|c|c|c|c|}
\hline Problem type & 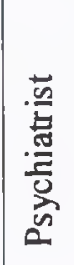 & 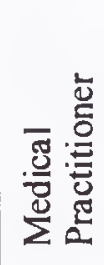 & 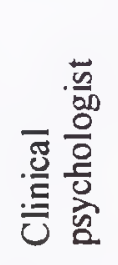 & 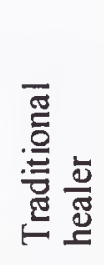 & 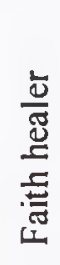 & 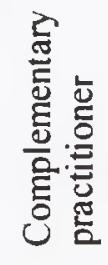 \\
\hline 1. Depression & 64 & 35 & 55 & 08 & 12 & 10 \\
\hline 2. Anxiety & 43 & 44 & 52 & 05 & 13 & 07 \\
\hline 3. Stress & 48 & 45 & 46 & 05 & 12 & 10 \\
\hline 4. Psychosocial & 45 & 23 & 50 & 08 & 10 & 08 \\
\hline 5. Bereavement & 18 & 38 & 37 & 08 & 30 & 06 \\
\hline 6. Substance use & 57 & 36 & 44 & 04 & 08 & 05 \\
\hline 7. Sexual abuse & 30 & 39 & 60 & 01 & 07 & 11 \\
\hline 8. Terminal illness & 04 & 52 & 16 & 07 & 35 & 14 \\
\hline 9. Asthma & 02 & 75 & 11 & 04 & 10 & 16 \\
\hline 10. Allergies & 04 & 75 & 02 & 04 & 04 & 16 \\
\hline 11. Cancer & 06 & 62 & 12 & 12 & 13 & 19 \\
\hline 12. Insomnia & 31 & 42 & 48 & 04 & 10 & 11 \\
\hline 13. HIV/AIDS & 06 & 62 & 30 & 13 & 11 & 20 \\
\hline 14. Stopping smoking & 13 & 46 & 35 & 06 & 23 & 23 \\
\hline
\end{tabular}

(3) "A mother on psychiatric treatment of depression was referred by a nurse to attend a church conference. She was prayed for and was healed."

(4) "A patient refused mastectomy as it was still early for operation. A nurse referred her to a traditional healer for treatment. She took treatment for 3 months. Thereafter the mass disappeared, and the patient was healed."

(5) "A subordinate who experienced work related stress that affected his productivity. His supervisor recommended mas sage therapy and a gym for stress relieving exercises."

\section{Knowledge}

When asked to evaluate the statement "Nurses should have knowledge about the most prominent ethnomedical treatments", the highest rating was given for faith healing (4.3), followed by complementary therapies (4.2), and traditional healing (4.1) (see Table 8).

About one fifth (22\%) of the participants had attended lectures or workshops or received training in the use of ethnomedical therapy. Workshop topics included herbal medicine and acupuncture (8\%). each modality from 1 (unfamiliar) to 3 (understand proposed medicinal uses) (see Table 9).

The calculated means indicated that faith healing was best understood and acupuncture was least understood (2.1 and 1.3 , respectively).

\section{Treatment outcomes and scientific evidence}

When asked whether the use of ethnomedical therapy would result in favourable or unfavourable treatment outcomes, more than $80 \%$ of the nurses thought that there would be 'some' positive outcome. However, more than $68 \%$ thought there would be 'some' negative outcome. There was also a high rate of 'don't know' answers (66\% to $75 \%$ ) (see Table 10 ).

Using the following 5-point Likert scale, participants were asked to evaluate 9 types of evidence in ethnomedical treatments and the impact of each on their thinking:

(1) This type of evidence would have no impact on my thoughts about ethnomedical treatments.

(2) This type of evidence would catch my attention but have no impact on my opinion of this treatment.

(3) I would look at the treatment more favourably but would 
not consider this proof of effectiveness.

(4) This type of evidence would convince me that the treatment is at least somewhat effective.

(5) This type of evidence would convince me that the treat ment is highly effective.

Nurse practitioners indicated that personal experience would provide the most convincing evidence of the efficacy of a ethnomedical modality ( $\mathrm{M}=2.87)$, followed by recommendation of a specialist $(M=2.83)$, and case reports in complementary medicine journals $(M=2.81)$. The break down for each category is presented in Table 11 .

\section{Discussion}

Generally, nurse practitioners ranked faith healing as most important, followed by complementary medicine practitioner and traditional healing in that order. This may be explained by the African cultural and religious background of the nurses. There was both a high positive and negative attitude towards any of the three ethnomedical therapies, which seems to indicate that the quality differs. This needs to be further investigated. Surely, the role of ethnomedical therapies in rural health care has been identified and a positive attitude towards their integration into the national health care system has been expressed (se also Osei 1994: 39, Ryan 1998: 209).

In line with other studies (e.g. Mohape \& Peltzer 1998: 39) the majority of the psychiatric nurses favoured the integration of faith healing (98\%), traditional healing (93\%), and complementary medicine $(77 \%)$ into the national health care system. These psychiatric nurses were all African South Africans; most were Protestants $(60 \%)$, followed by Roman Catholics (19\%) and other religious denominations such as Zion Christian Church and Jehovah's Witnesses.

However, low rates of referral to a faith healer, complementary medicine practitioner and traditional healers were practised, and the majority discussed rather the harmful effects than the benefits of ethnomedical therapies. This may indicate some opposition in the collaboration of the nurses with ethnomedical therapies. Nurses in Botswana were also found to be opposed medical health system (Barbee 1986: 75). Among nurses in Malawi, a number of cultural conflicts were identified: (1) conflict with traditional healing and medicine, (2) conflict with traditional diet and feeding practices, (3) conflict with family/gender taboos, (4) conflict with concepts of illness, (5) conflict with religion, (6) conflict with sexual practices, (7) conflict with family planning, and (8) conflict with "death". Further it was found that the nurses generally would ask the patient about the belief underlying her/his cultural practice. Thereafter the nurse will try to convince the patient about a biomedical concept of health and health care (Peltzer 1997: 159).

This study found that patients had often consulted traditional healers before coming to the clinic, in particular for conditions such as tuberculosis, HIV/AIDS, cancer, renal failure, epilepsy and sexually transmitted diseases.

Generally, there seemed to have been low referral rates by the nurse clinicians to any of the ethnomedical practitioners (14\% to traditional healers, $22 \%$ to faith healers and $26 \%$ to complementary medical practitioners). For example, in the UK Perkin, Pearcy and Fraser (1994: 523) found that $70 \%$ of hospital doctors and $93 \%$ of general practitioners had, on at least one occasion, suggested a referral for complementary treatment.

Patients normally initiated discussing the benefits and nurses normally initiated the harmful effects of traditional and faith healing. This means that patients and nurses may have differing views on the value of traditional and faith healing. On the other hand, in regard to the treatment outcome of ethnomedical therapies most nurses acknowledged positive effects, which was also found in other studies (e.g., Farrand 1984: 779).

\section{Recommendations}

The study provided evidence that there is a two way referral process of clients/patients from a healer to a nurse and from a nurse to a healer. Therefore, it is important that healers and primary health care nurses have forums to share experiences concerning their beliefs and treatment modalities of health prob-

\section{Table 8: Mean ratings of nurses 'knowledge about ethnomedical therapy (from $1=$ srongly disagree to $6=$ strongly agree}

\begin{tabular}{|l|l|l|}
\hline Knowledge about treatment modalities & Mean & SD \\
\hline $\begin{array}{l}\text { Nurses should have knowledge about the most prominent } \\
\text { faith healing therapies }\end{array}$ & 4.30 & 1.48 \\
\hline $\begin{array}{l}\text { Nurses should have knowledge about the most prominent } \\
\text { complementary therapies }\end{array}$ & 4.20 & 1.52 \\
\hline $\begin{array}{l}\text { Nurses should have knowledge about the most prominent } \\
\text { traditional healing therapies }\end{array}$ & 4.14 & 1.57 \\
\hline
\end{tabular}

to the collaboration with spiritual and traditional healers. They were perceived to be caught in a dialectical tension between their traditional beliefs and their acquired beliefs in the bio- lems prevalent in the communities.

Further research is needed to explore the cultural beliefs of primary health care nurses about health and illness, and how these beliefs have an impact on their practice as nurses. 
A nurse has a role to assist a patient to choose among different ethnomedical therapies for the sake of the patient's well-being. Therefore, there is a need that nurses understand and respect the patient's value system with regard to his or her choice about maintaining good health. In order to improve the quality of traditional, faith healing and complementary medicine, the
Health and Welfare, Northern Province, for giving permission to conduct the study.

\section{References}

AFRICAN NATIONAL CONGRESS 1994A: A national health plan for South Africa. Johannesburg: Author.

Table 9: Self-report knowledge of ethnomedical therapy in percent, mean and standard deviation

\begin{tabular}{|l|l|l|l|l|l|}
\hline Modality & $\begin{array}{l}\text { Unfami- } \\
\text { lar }\end{array}$ & $\begin{array}{l}\text { Rudimentary } \\
\text { under- } \\
\text { Standing }\end{array}$ & $\begin{array}{l}\text { Understanding } \\
\text { of proposed uses }\end{array}$ & Mean & SD \\
\hline Massage & 41 & 34 & 35 & 1.9 & 0.8 \\
\hline Hypnosis & 67 & 19 & 12 & 1.5 & 0.8 \\
\hline Homeopathy & 54 & 31 & 15 & 1.6 & 0.7 \\
\hline Chiropractic & 71 & 21 & 08 & 1.4 & 0.6 \\
\hline Herbal therapy & 40 & 41 & 19 & 1.8 & 0.7 \\
\hline Acupuncture & 77 & 18 & 06 & 1.3 & 0.6 \\
\hline Faith healing & 20 & 46 & 34 & 2.1 & 0.7 \\
\hline Divination & 73 & 17 & 10 & 1.4 & 0.7 \\
\hline Touch therapy & 52 & 25 & 21 & 1.7 & 0.8 \\
\hline Vitamin therapy & 41 & 34 & 25 & 1.8 & 0.8 \\
\hline
\end{tabular}

Table 10 : Would the use of traditional healing, faith healing or alternative medicine result in favourable or unfavourable treatment outcomes in percent

\begin{tabular}{|l|l|l|l|}
\hline Treatment outcome & Traditional healing & Faith healing & $\begin{array}{l}\text { Complementary } \\
\text { medicine }\end{array}$ \\
\hline Major positive & 47 & 58 & 46 \\
\hline Some positive & 80 & 85 & 88 \\
\hline Neither & 64 & 58 & 66 \\
\hline Some negative & 73 & 68 & 70 \\
\hline Major negative & 31 & 36 & 35 \\
\hline Don't know & 66 & 68 & 75 \\
\hline
\end{tabular}

sectors in which they can be most effective should be identified such as psycho-social and mental instability seem to be some of them (Peltzer 2001: 10).

\section{Acknowledgement}

The University of the North Research Office has funded the study. In addition, the researchers thank the Department of 


\section{Table 11: Physicians 'evaluation of types of evidence for traditional and faith healing as well}

as alternative medicine in percent

\begin{tabular}{|l|l|l|}
\hline Item & Mean & SD \\
\hline Prospective clinical randomized control trials & 2.03 & 1.14 \\
\hline Evidence demonstrating physiologic mechanism & 2.44 & 1.36 \\
\hline Retrospective case control studies in standard medical journals & 2.36 & 1.23 \\
\hline Personal experience & 2.87 & 1.43 \\
\hline Case reports in standard medical journals & 2.60 & 1.53 \\
\hline Recommendations of respected colleagues & 2.51 & 1.37 \\
\hline $\begin{array}{l}\text { Recommendation of a specialist to whom you have referred the } \\
\text { patient }\end{array}$ & 2.83 & 1.36 \\
\hline Case reports in complementary medicine journals & 2.81 & 1.26 \\
\hline $\begin{array}{l}\text { Recommendations of family and friends who have used the } \\
\text { therapy }\end{array}$ & 2.66 & 1.37 \\
\hline
\end{tabular}

AFRICAN NATIONAL CONGRESS 1994B: The Reconstruction and Development Programme. Johannesburg: Author.

AKERELE, O 1987: The best of both worlds: bringing traditional medicine up to date. Social Science and Medicine 24: 177-181.

BARBEE, EL 1986: Biomedical resistance to ethnomedicine in Botswana. Social Science and Medicine 22: 75-80.

DEVELOPMENT BANK OF SOUTHERN AFRICA 1988: Northern Province Development Profile. Johannesburg: Author.

ARRAND, D 1984: Is a combined western and traditional health service for black patients desirable? South African Medical Journal 66: 779-780.

FENN, C 1998: A guide to complementary therapies in South Africa. Cape Town: Struik Publishers.

FREEMAN, M \& MOTSEI, M 1992: Planning health care in South Africa: is there a role for traditional healers? Social Science \& Medicine 34: 1183-1090.

HOPA, M, SIMBAYI, LC \& DU TOIT, CD 1998: Perceptions on integration of traditional and western healing in the new South Africa. South African Journal of Psychology 28: 814.

KLEINMAN, A 1980: Patients and healers in the context of culture. Berkeley: University of California Press.

LOUW, DA \& PRETORIUS, E 1995: The traditional healer in a multicultural society: the South African experience. In: L.L.
Adler \& B.R. Mukherji (Eds.) Spirit versus scalpel: traditional healing and modern psychotherapy (pp. 41-58). London: Bergin \& Garrey.

MABUNDA, MM 1999: A cultural evaluation of the causes and treatment of diseases and other misfortunes among communities in the Pietersburg and Mankweng areas of the Northern Province. MA Dissertation in Anthropology. Sovenga: University of the North.

MAHAPE, JD \& PELTZER, K 1998: Attitudes of psychiatric nurses towards traditional healers in South Africa.Journal of Psvchologv in Africa 8 : 39-50.

NEMEC, J 1980: Re-discovering an ancient resource. Contact 58: $1-18$.

OSEI, Y 1994: Psychiatric services in a developing country: the case of Ghana. Curare 17: 39-43.

PELTZER, K 1998: A community survey of traditional healers in South Africa (Northern Province). South African Journal of Ethnologv 21: 191-197

PELTZER, K 1997: Psychocultural contexts of nursing in Malawi: sources of stress, burn-out, coping and satisfiers. $P_{S 2}-$ chopathologv Africaine 28: 149-176.

PELTZER, K 1999: Faith healing for mental and social disorders in the Northern Province (South Africa). Journal of Religion in Africa 29: 387-402.

PELTZER, K 2001: An investigation into the practices of traditional and faith healing in an urban setting in South Africa. Health SA Gesondheid 6: 3-14. 
PERKIN, MR; PEARCY, RM \& FRASER, JS 1994: A comparison of the attitudes shown by general practitioners, hospital doctors and medical students towards complementary medicine. Journal of the Royal Society of Medicine 87: 523-525.

PRETORIUS, E 1989: Skakeling tussen tradisionele en moderne geneeskunde in Afrika; die dekade sedert Alma Ata. ActaAcademica 21: 101-129.

PRETORIUS, E 1999: In the home stretch: the legalisation of African traditional healing in South Africa. Acta Academica 31: 1-17.

RYAN, GW 1998: That do sequential behavioural patterns suggest about the medical decision-making process? Social Science a Medicine 46: 209-225.

SHAI-MAHOKO, SN 1996: Indigenous healers in the North West Province: a survey of their clinical activities in health care in the rural areas. Curationis 19: 31-34.

SWARTZ, L 1986: Transcultural psychiatry in South Africa (Part 1). Transcultural Psvchiatric Research Review 23: 273 303.

VAN DER GEEST, $S$ 1997: Is there a role for traditional medicine in basic health services in Africa? A plea for a community perspective. Tropical Medicine and International Health 2: 903-911.

WHO 1976: Traditional medicine and its role in the development of health services in Africa (AFR/RC26/TD/1). Brazzaville: WHO. 